Revista Brasileira de Agricultura Irrigada v.10, nº.1, p. 460 - 467, 2016

ISSN 1982-7679 (On-line)

Fortaleza, CE, INOVAGRI - http://www.inovagri.org.br

DOI: 10.7127/rbai.v10n100372

Protocolo 372.16 - 16/11/2015 Aprovado em 02/02/2016

\title{
PRODUTIVIDADE DE CULTIVARES DE CENOURAS IRRIGADAS EM DIFERENTES ESPAÇAMENTOS ENTRE PLANTAS
}

\author{
Geraldo Milanez de Resende ${ }^{1 *}$, Nivaldo Duarte Costa ${ }^{2}$, Jony Eshi Yuri ${ }^{1}$, José Hortêncio \\ Mota $^{3}$
}

\section{RESUMO}

A cenoura é a quarta hortaliça mais consumida no país e uma das mais consumidas no mundo. Com o objetivo de avaliar o desempenho produtivo de cultivares de cenoura em diferentes espaçamentos entre plantas conduziu-se um experimento no período de maio a agosto de 2013, em Petrolina, PE. Utilizou-se o delineamento de blocos ao acaso em esquema fatorial 2 $\mathrm{x} 4$, compreendendo duas cultivares (Brasília e Alvorada) e quatro espaçamentos entre plantas (4, 6, 8 e $10 \mathrm{~cm}$ ), com três repetições. A altura de plantas de cenoura oscilou de 56,3 a 57,0 cm para cultivares e 56,2 a 57,2 cm para espaçamentos entre plantas, não se observando diferenças significativas para tratamentos. A cultivar Brasília sobressaiu-se com maior massa fresca com 92,1 $\mathrm{g} \mathrm{raiz}^{-1}$ em relação a cultivar Alvorada (83,3 $\mathrm{g} \mathrm{raiz}^{-1}$ ) e o maior espaçamento $(10 \mathrm{~cm})$ proporcionou a maior massa fresca com 105,1 $\mathrm{g} \mathrm{raiz}^{-1}$. Maior produtividade total de raízes (58,2 $\mathrm{t} \mathrm{ha}^{-1}$ ) foi alcançada pela cultivar Brasília e pelo espaçamento de $4 \mathrm{~cm}$ entre plantas $\left(63,3 \mathrm{t} \mathrm{ha}^{-1}\right)$. Para produtividade comercial os resultados demonstraram efeitos da interação, onde constataram-se para as cultivares Brasília e Alvorada maior produtividade no espaçamento de $4 \mathrm{~cm}$ entre plantas (61,5 e 49,9 $\mathrm{t} \mathrm{ha}^{-1}$, respectivamente).

Palavras-chave: Daucus carota, rendimento, densidade.

\section{YIELD OF CARROT CULTIVARS IRRIGATED AT DIFFERENT PLANT SPACING}

\section{ABSTRACT}

The carrot is the fourth most consumed vegetable in the country and one of the most consumed worldwide. The objective of this work was to analyze the yield performance of carrot cultivars in different plant spacings. The experiment was carried out from May to August 2013, in Petrolina, PE, Brazil, using a randomized block design in a factorial 2 x 4, consisting of two cultivars (Brasília and Alvorada) and four spacing between plants within the row $(4,6,8$ and $10 \mathrm{~cm})$ and three replications. The height of carrot plants ranged from 56.3 to

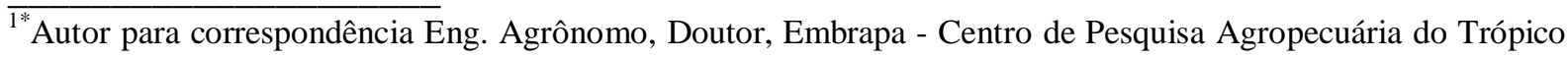
Semiárido.e-mails: geraldo.milanez@embrapa.br; jony.yuri@embrapa.br

${ }^{2}$ Eng. Agrônomo, Doutor, Embrapa - Centro de Pesquisa Agropecuária do Trópico Semiárido. E-mail: nivaldo.costa@embrapa.br;

${ }^{3}$ Eng. Agrônomo, Doutor, Universidade Federal de Goiás/Campus Jataí; e-mail: hortencio.mota@terra.com.br
} 
$57.0 \mathrm{~cm}$ for cultivars and 56.2 to $57.2 \mathrm{~cm}$ spacing between plants, without significant differences among treatments. Highest total roots yield roots $\left(58.2 \mathrm{t} \mathrm{ha}^{-1}\right)$ was showed by Brasília cultivar and the spacing of $4 \mathrm{~cm}$ between plants $\left(63.3 \mathrm{t} \mathrm{ha}^{-1}\right)$. The cultivar Brasilia showed more fresh mass with $92.1 \mathrm{~g} \mathrm{root}^{-1}$ in relation to Alvorada cultivar $\left(83.3 \mathrm{~g} \mathrm{root}^{-1}\right.$ ) and wider spacing $(10 \mathrm{~cm})$ provided the largest fresh mass with $105.1 \mathrm{~g} \mathrm{root}^{-1}$. For commercial yield the results demonstrated interaction effects, which were evidenced for the Brasília and Alvorada cultivars more yield at a spacing of $4 \mathrm{~cm}$ between plants $\left(61.5\right.$ and $49.9 \mathrm{t} \mathrm{ha}^{-1}$, respectively).

Keywords: Daucus carota, yield, density.

\section{INTRODUÇÃO}

A cenoura (Daucus carota L.) é a entre as hortaliças, cujas partes comestíveis e de maior valor econômico são as raízes, apresentando alto conteúdo de vitamina A, textura macia, paladar agradável (FILGUEIRA, 2008); além de elevada capacidade de geração de emprego e renda, em todos os segmentos de sua cadeia produtiva, durante o ano inteiro (VILELA; BORGES, 2008).

A produção nacional em 2012, foi de 780,8 mil toneladas, cultivadas em uma área de 26,5 mil hectares com produtividade média de 29,5 $\mathrm{t} \mathrm{ha}^{-1}$ (EMBRAPA HORTALIÇAS, 2015), enquanto a nível mundial foram produzidas 36,9 milhões de toneladas, cultivadas em área de 1,19 milhões de hectares, o que proporcionou produtividade média de 30,8 $\mathrm{t} \mathrm{ha}^{-}$ ${ }^{1}$ (FAO, 2015).

Cultivares de verão, como a Brasília, e aquelas do grupo Kuroda, adaptam-se bem às chuvas e temperaturas elevadas; já as cultivares de inverno, como os do grupo Nantes, produzem melhor sob temperaturas amenas ou frias, entre 16 e $20^{\circ} \mathrm{C}$ (SOUZA; RESENDE, 2003). As condições climáticas que ocorrem nas diferentes épocas e locais de cultivo podem influenciar a adaptabilidade e a estabilidade das cultivares (OLIVEIRA et al., 2005). Assim, na maioria das vezes a temperatura ambiente é determinante na escolha da cultivar (REGHIN; DUDA, 2000).

Em plantio no outono-inverno, Luz et al. (2009) verificaram produtividade total entre 29,6 e 37,8 t ha ${ }^{-1}$. Para produtividade comercial, não foram observadas diferenças entre as cultivares, com variações entre 20,8 e 28,7 t ha-1 ${ }^{-1}$ Segundo Filgueira (2008) em São
Gotardo-MG, obtêm-se 50,0 t ha-1 de raízes com relativa facilidade em condições de campo, em solo sob cerrado, aplicando-se calagem e adubação mineral.

As propostas de se avaliar os espaçamentos de plantio, para as culturas em geral, têm procurado atender às necessidades específicas dos tratos culturais e a melhoria da produtividade. Todavia, alterações em espaçamentos induzem uma série de modificações no crescimento e no desenvolvimento das plantas e necessitam de melhores esclarecimentos. No caso específico da população de plantas, tem sido verificado em trabalhos, que os resultados variam de acordo com os cultivares, e também com as regiões produtoras (LOPES et al., 2008). Para a cultura da cenoura são relatados espaçamentos que variam de 15 a $25 \mathrm{~cm}$ ou, ainda até $30 \mathrm{~cm}$ entre linhas e de 5 a $7 \mathrm{~cm}$ entre plantas (SOUZA et al., 2002; FILGUEIRA, 2008).

Pelo exposto, o presente trabalho teve como objetivo avaliar o comportamento produtivo de cultivares de cenoura irrigadas em diferentes espaçamentos entre plantas.

\section{MATERIAL E MÉTODOS}

O experimento foi conduzido no período de maio a agosto de 2013, em Petrolina-PE (0909' S, 40 $22^{\prime} \mathrm{W}, 365,5 \mathrm{~m}$ de altitude). O solo classificado como Argissolo Vermelho - Amarelo Eutrófico Plíntico (SANTOS et al., 2006), com as seguintes características: $\mathrm{pH}\left(\mathrm{H}_{2} \mathrm{O}\right)=5,6 ; \mathrm{Ca}^{2+}=2,3$ $\mathrm{cmol}_{\mathrm{C}} \cdot \mathrm{dm}^{3} ; \mathrm{Mg}^{2+}=0,7 \mathrm{cmol}_{\mathrm{C}} \cdot \mathrm{dm}^{3} ; \mathrm{K}^{+}=0,30$

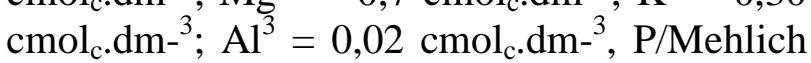
= 5,2 mg. $\mathrm{dm}^{-3}$ e M.O. = 5,3 g. $\mathrm{kg}^{-1}$ e físicas (\%): 
areia $=81 ;$ silte $=11$ e argila $=8$. As ocorrências climáticas durante a execução do trabalho foram de temperatura média de $24,4^{\circ} \mathrm{C}$, com mínima em $19,0^{\circ} \mathrm{C}$ e máxima de $30,4^{\circ} \mathrm{C}$, umidade relativa do ar de $63,5 \%$ e precipitação pluviométrica acumulada no período de $26,9 \mathrm{~mm}$.

O delineamento experimental utilizado foi de blocos casualizados, sendo os tratamentos dispostos em fatorial $2 \times 4$, compreendendo duas cultivares (Brasília e Alvorada) e quatro espaçamentos entre plantas $(4,6,8$ e $10 \mathrm{~cm})$, com quatro repetições.

O preparo do solo constou de uma aração, gradagem e confecção dos canteiros a $0,25 \mathrm{~m}$ de altura, com 2,0 m de comprimento e $1,20 \mathrm{~m}$ de largura $\left(2,40 \mathrm{~m}^{2}\right)$, perfazendo um total de dez linhas de plantio. Como área útil da parcela se utilizaram as seis linhas centrais, retirando duas linhas em cada extremidade $\left(1,44 \mathrm{~m}^{2}\right)$. Utilizou-se o espaçamento $20 \mathrm{~cm}$ entre linhas, sendo a semeadura realizada diretamente no canteiro transversalmente, em maio de 2013. O desbaste foi realizado aos 25 dias após a semeadura, adequando-se os quatro espaçamentos a serem avaliados de 4, 6, 8 e 10 $\mathrm{cm}$.

A adubação de plantio constou de $40 \mathrm{t}$ $\mathrm{ha}^{-1}$ de esterco caprino, $40 \mathrm{~kg} \mathrm{ha}^{-1}$ de nitrogênio, $400 \mathrm{~kg} \mathrm{ha}^{-1}$ de fósforo e $60 \mathrm{~kg} \mathrm{ha}^{-1}$ de potássio. Foram utilizados ainda em cobertura $80 \mathrm{~kg} \mathrm{ha}^{-1}$ de nitrogênio e $120 \mathrm{~kg} \mathrm{ha}^{-1}$ de potássio, parcelados aos 20 e 40 dias após a emergência (ALVAREZ et al., 1999). Como fonte dos nutrientes foram utilizados uréia, superfosfato simples e cloreto de potássio.

A cultura foi mantida no limpo por meio de capinas manuais. Utilizou-se irrigação por microaspersão com lâminas em torno de 10 $\mathrm{mm}$, três vezes por semana, baseadas na evaporação do tanque classe A (MAROUELLI et al., 2007). Não foram realizados quaisquer tratos fitossanitários, e durante a condução do ensaio observou-se um bom desenvolvimento vegetativo da cultura.

A colheita foi realizada em agosto de 2013, quando as folhas apresentavam leve tombamento e amarelecimento, indicativo do ponto de colheita. Foram avaliadas a altura de plantas em centímetros (medida do solo até a extremidade da folha mais alta), produtividade total e comercial de raízes ( $\mathrm{t} \mathrm{ha}^{-1}$ ) e massa fresca da raiz (g). Como produtividade comercial foram consideradas as raízes com 10 a $22 \mathrm{~cm}$ de comprimento, diâmetro entre 2-4 $\mathrm{cm}$, sem ombro verde, livres de rachaduras, bifurcações e danos mecânicos.

Os dados coletados foram submetidos à análise de variância para cada característica avaliada e seus efeitos avaliados pelo teste de $\mathrm{F}$ a $5 \%$ de probabilidade. As médias para cultivar foram comparadas pelo teste de $\mathrm{F}$ a $5 \%$ de probabilidade e para espaçamentos entre plantas foram ajustadas a equações de regressão adotando-se como critério para escolha do modelo, o efeito significativo pelo teste de $\mathrm{F}$ a $5 \%$ de probabilidade e a magnitude dos coeficientes de determinação. As análises foram realizadas com o auxílio do programa SISVAR 5.0 (FERREIRA, 2011).

\section{RESULTADOS E DISCUSSÃO}

Não foi observado efeito significativo para altura de plantas entre tratamentos. Os valores variaram entre 56,3 e 57,0 para cultivares e 56,2 a 57,2 cm para espaçamentos entre plantas. Estes resultados concordam com os obtidos por Bernardi et al. (2004), que avaliando cultivares em diferentes espaçamentos de plantio, também não verificaram diferenças na altura de plantas, que oscilou entre 56,8 a 61,8 cm. Ao contrário, Kabir et al. (2013) encontraram, para os maiores espaçamentos, maior altura das plantas. Em geral, altas densidades populacionais resultam em menor altura de planta (RAJASEKARAN et al., 2006).

Efeitos independentes foram verificados para produtividade total de raízes, na qual a cultivar Brasília com 58,2 $\mathrm{t} \mathrm{ha}^{-1}$ foi superior a cultivar Alvorada que alcançou 53,3 $\mathrm{t} \mathrm{ha}^{-1}$ (Tabela 1). Em plantio no outono-inverno, Luz et al. (2009) verificaram menor produtividade total oscilando entre 29,6 e 37,8 $\mathrm{tha}^{-1}$. 
Tabela 1. Produtividade total e massa fresca de raízes de cultivares de cenoura. Petrolina - PE, 2013.

$\begin{array}{ccr} & \text { Massa fresca } & \text { Produtividade } \\ \text { Cultivar } & \left(\mathrm{g} \mathrm{raiz}^{-1}\right) & \left(\mathrm{t} \mathrm{ha}^{-1}\right)\end{array}$

\begin{tabular}{lcc}
\hline Brasília & $92,1 \mathrm{a}$ & $58,2 \mathrm{a}$ \\
Alvorada & $83,3 \mathrm{~b}$ & $53,3 \mathrm{~b}$ \\
C.V. $(\%)$ & 6,3 & 5,2 \\
\hline
\end{tabular}

*Médias seguidas da mesma letra nas colunas não diferem entre si pelo teste de $\mathrm{F}$ a 5 \% de probabilidade.

Analisando o espaçamento entre plantas verificaram-se redução na produtividade total de raízes com o aumento do espaçamento. Maior produtividade foi obtida se utilizando o espaçamento de $4 \mathrm{~cm}$ entre plantas $\left(63,3 \mathrm{t} \mathrm{ha}^{-1}\right)$, com pior desempenho apresentado pelo espaçamento de $10 \mathrm{~cm}$ que resultou em 48,3 t ha $^{-1}$, ou seja, 23,7\% inferior (Figura 1). Lopes et al. (2008) avaliaram os espaçamentos entre linhas (15 e $20 \mathrm{~cm})$ e entre plantas (4, 6 e 8 $\mathrm{cm})$ e obtiveram maiores produtividades também no espaçamento $4 \mathrm{~cm}$ entre plantas. O arranjo das plantas é um fator do ambiente que afeta diretamente a produtividade, número e qualidade de raízes comercializáveis da cenoura (BEZERRA NETO et al., 2006; LOPES et al., 2008; ALVES et al., 2010).

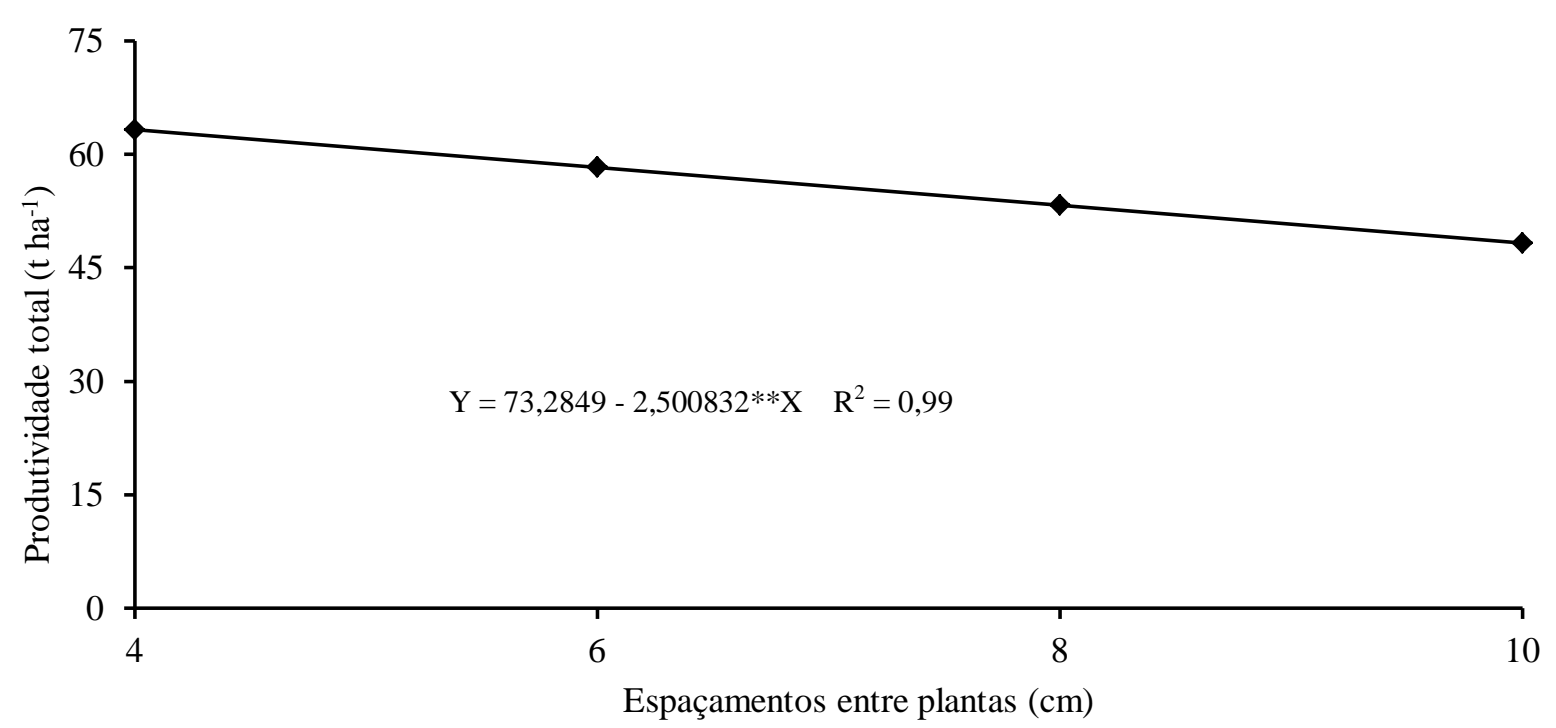

Figura 1. Produtividade total de raízes de cenoura em função do espaçamento entre plantas. PetrolinaPE, 2013.

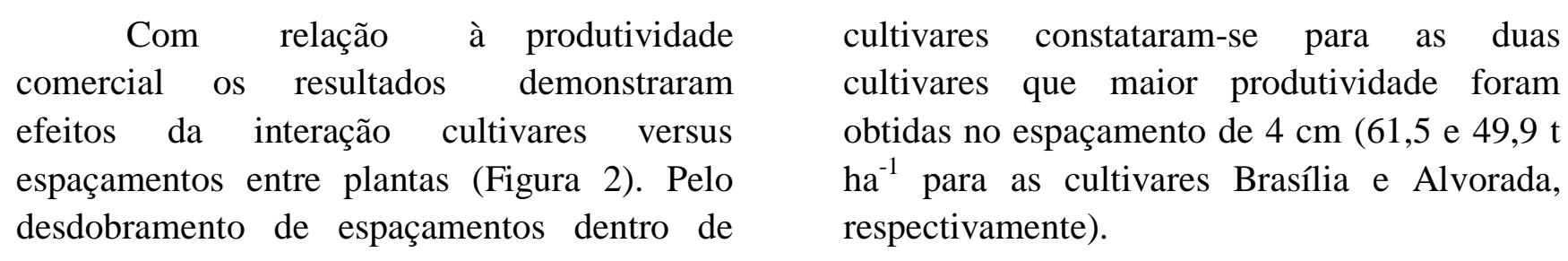




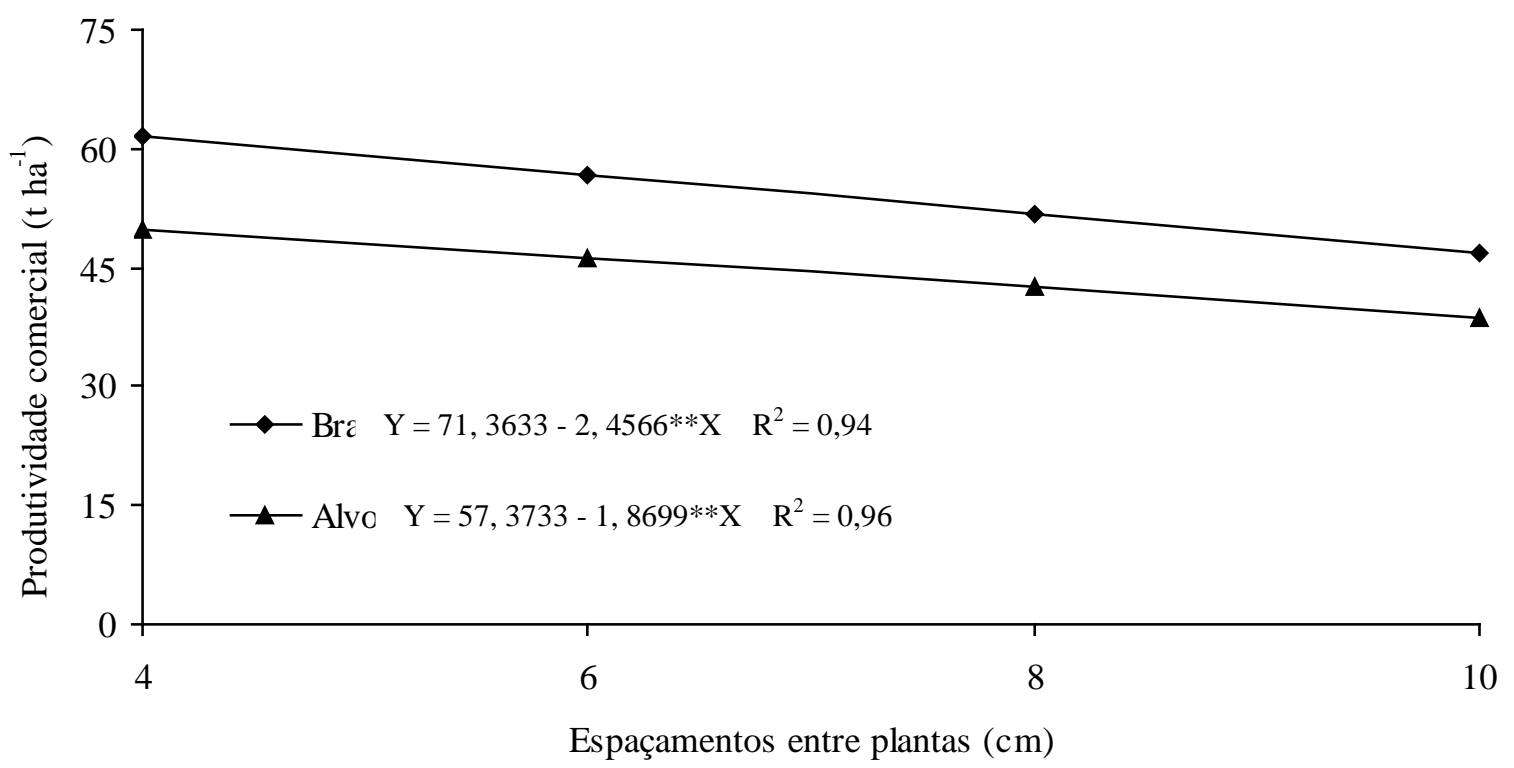

Figura 2. Produtividade comercial de raízes de cenoura em função do espaçamento entre plantas. Petrolina-PE, 2013.

Comparativamente ao maior espaçamento de $10 \mathrm{~cm}$ entre plantas observa-se um redução gradativa da ordem de $24 \%$ para a cultivar Brasília, e de $22 \%$ para a cultivar Alvorada, demonstrando que o incremento do espaçamento na cultura, apesar de promover raízes de maior massa fresca (como discutido abaixo), não se expressa em produtividade superior, independente da cultivar utilizada. A produtividade comercial de cenoura aumenta à medida que se aumenta a densidade populacional, e está diretamente relacionado ao maior número de plantas (BARROS JÚNIOR, 2004), o que corrobora com os resultados obtidos nesse trabalho. A cultivar Brasília foi superior estatisticamente a cultivar Alvorada, em todos os espaçamentos avaliados. Esse comportamento produtivo concorda com os resultados obtidos por Lopes et al. (2008). Todavia, Oliveira et al. (2008) e Luz et al. (2009), não verificaram entre as duas cultivares, diferenças de produtividade. Estas respostas indicam os diferentes graus de adaptação das cultivares às diferentes condições edafoclimáticas locais, em termos de solo, ambiente, genótipo e sua interação, o que intluencia diretamente o seu desempenho produtivo.

Efeitos significativos independentes dos fatores estudados foram observados para massa fresca de raízes. A cultivar Brasília sobressaiuse com maior massa fresca $\left(92,1 \mathrm{~g} \mathrm{raiz}^{-1}\right)$ em relação a cultivar Alvorada que obteve 83,3 g raiz $^{-1}$ (Tabela 1). Lopes et al. (2008) confirmam a superioridade da cultivar Brasília, relatando ser este resultado em função da melhor adaptação da cultivar, às condições locais de cultivo. Lima; Athanázio (2008) e Salgado et al. (2006) encontraram para a mesma cultivar respectivos 140,8 e 117,3 g raiz ${ }^{-1}$, ou seja, valores acima dos encontrados nesse trabalho. É interessante reafirmar, que às diferentes condições edafoclimáticas locais, influenciam diretamente no desempenho das cultivares, consequentemente no seu rendimento em termos de massa fresca.

No que se refere ao espaçamento entre plantas, verificou-se efeito linear com o incremento do espaçamento. $\mathrm{O}$ maior espaçamento $(10 \mathrm{~cm})$ proporcionou a maior massa fresca com 105,1 $\mathrm{g} \mathrm{raiz}^{-1}$, seguido do espaçamento de $8 \mathrm{~cm}\left(93,5 \mathrm{~g} \mathrm{raiz}^{-1}\right)$, de $6 \mathrm{~cm}$ $\left(81,9 \mathrm{~g} \mathrm{raiz}^{-1}\right)$ e $4 \mathrm{~cm}\left(70,3 \mathrm{~g} \mathrm{raiz}^{-1}\right)$ (Figura 3). 
Em termos percentuais o menor espaçamento produziu raízes 33,1\% menos pesadas, o que é compensado pela maior população de plantas por hectare.

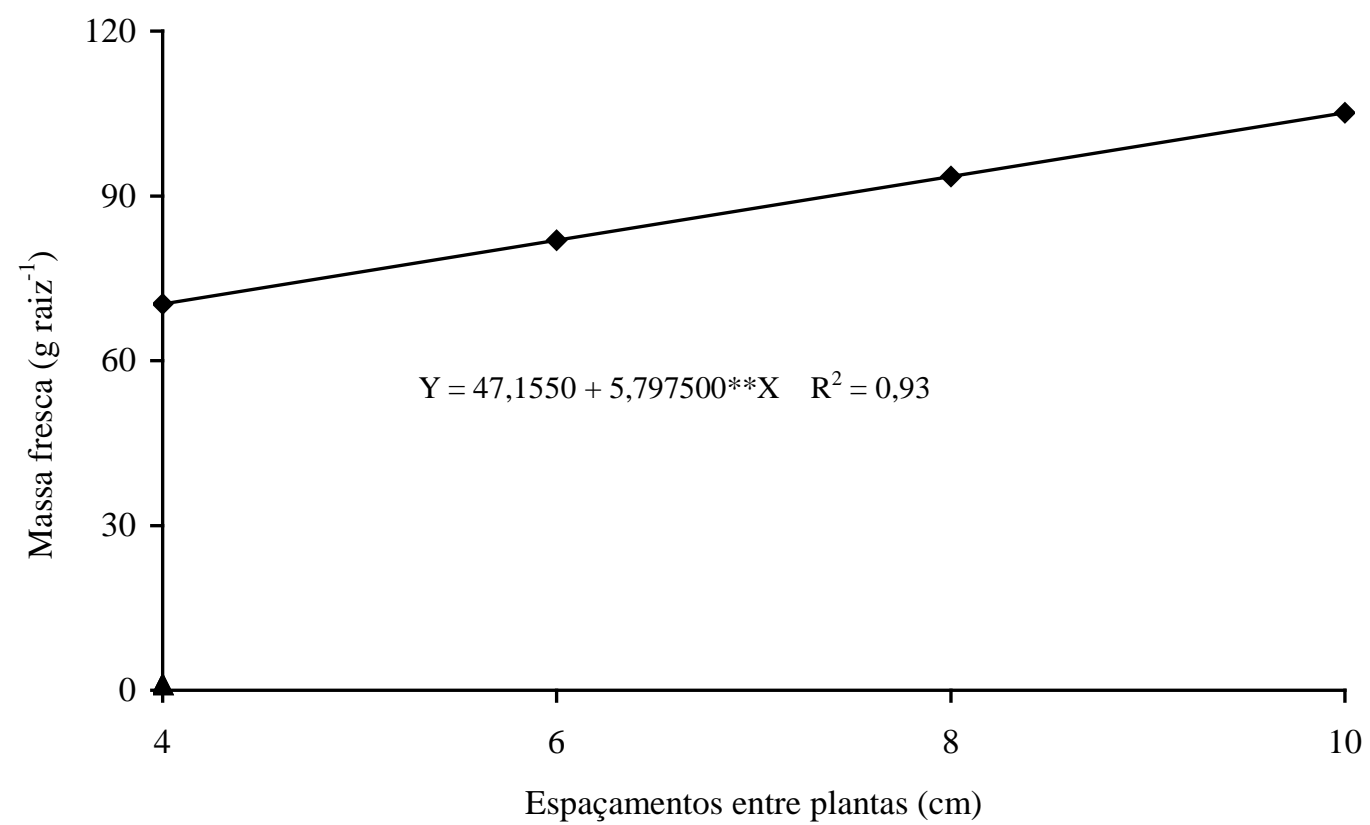

Figura 3. Massa fresca de raíz de cenoura em função do espaçamento entre plantas. Petrolina-PE, 2013.

Estes resultados são alicerçados por Rajasekaran et al. (2006), Lopes et al. (2008) e Alves et al. (2010), que verificaram para maiores populações menor massa fresca de raízes. Este comportamento ocorre devido à competição intraespecífica causada pelo aumento da pressão populacional na cenoura. Segundo Silva et al. (2003), o número elevado de plantas resulta em menor disponibilidade de radiação fotossintética para as folhas localizadas na parte inferior da planta, acarretando sombreamento e a redução da taxa fotossintética líquida por planta, resultando na formação de unidades produtivas menores, ou seja, raízes mais finas e com menor massa média. No entanto, até certo limite, ocorre a compensação da produção pela elevação do número de raízes.

\section{CONCLUSÕES}

O espaçamento de $10 \mathrm{~cm}$ entre plantas proporcionou a maior massa fresca de raiz nas duas cultivares, no entanto, sem apresentar maior produtividade.
O espaçamento de $4 \mathrm{~cm}$ entre plantas é o mais adequado para as cultivares avaliadas em termos produtivos e qualidade de raízes, sendo a cultivar Brasília a mais produtiva.

\section{REFERÊNCIAS}

ALVAREZ V.; H.V., DIAS; L.E., RIBEIRO; A.C.; SOUZA; R.B. Sugestões de adubação para hortaliças. In: RIBEIRO, A.C.; GUIMARÃES, P.T.G.; ALVAREZ V., V.H. (Ed.). Recomendação para o uso de corretivos e fertilizantes em Minas Gerais: 5 . Aproximação. Viçosa: Comissão de Fertilidade do Solo do Estado de Minas Gerais, 1999. p.6171-208.

ALVES, S.S.V.; NEGREIROS, M.Z.; AROUCHA, E.M.M.; LOPES, W.A.R.; TEÓFILO, T.M.S.; FREITAS, F.C.L; NUNES, G.H.S. Qualidade de cenouras em diferentes densidades populacionais. Revista Ceres, v. 57, n. 2, p. 218-223, 2010.

BARROS JÚNIOR, A.P. Densidades populacionais das culturas componentes no 
desempenho agroeconômico do consórcio cenoura e alface em bicultivo em faixa. $77 \mathrm{f}$. 2004. Dissertação (Mestrado em Fitotecnia). Escola Superior de Agricultura de Mossoró, Mossoró.

BERNARDI, V.F., FREITAS, J.A.; SILVA, V.A.R.; TULMANN NETO, A. Avaliação de espaçamentos de cenoura para os híbridos AF845 e AF750. Acta Scientiarum. Agronomy, v. 26, n. 2, p. 125-130, 2004.

BEZERRA NETO, F.; BARROS JÚNIOR, A.P.; SILVA, E.O.; NEGREIROS, M.Z.; OLIVEIRA, E.Q.; SILVEIRA, L.M.; CÂMARA, M.J.T.; NUNES, G.H.S. Qualidade nutricional de cenoura e alface cultivadas em Mossoró-RN em função da densidade populacional. Horticultura Brasileira, v. 24, n. 4, p. 476-480, 2006.

EMBRAPA HORTALIÇAS - CNPH. Situação das Safras de Hortaliças no Brasil - 20002012. Disponível em: http://www.cnph.embrapa.br. Acesso em: 19 agosto 2015.

FAO. Agricultural production, primary crops. Disponível em: http://www.fao.org. Acesso em: 8 junho 2015.

FERREIRA, D. F. Sisvar: a computer statistic alanalysis system. Ciência e Agrotecnologia, v. 35, n. 6, p. 1039-1042, 2011.

FILGUEIRA, F.A.R. Novo manual de olericultura: agrotecnologia moderna na produção e comercialização de hortaliças. Viçosa: Editora UFV, 3 ed., 2008. 421p.

KABIR, A., ARFAN, A.; WALIULLAH, M.H.; RAHMAN, M.M.M.; RASHID, A. Effect of spacing and sowing time on growth and yield of carrot (Daucus carrota L.). International Journal of Sustainable Agriculture, v. 5, n.1, p. 29-36, 2013.

LIMA, C.B.; ATHANÁZIO, J.C. Caracterização comercial de raízes de cenoura de seis ciclos de seleção da variedade Londrina. Semina: Ciências Agrárias, v. 29, n. 3, p. 507514, 2008.

LOPES, W.A.R.; NEGREIROS, M.Z.; TEÓFILO, T.M.S.; ALVES, S.S.V.; MARTINS, C.M.; NUNES, G.H.S.; GRANGEIRO, L.C. Produtividade de cultivares de cenoura em diferentes densidades de plantio. Revista Ceres, v. 55, n. 5, p. 482487, 2008.

LUZ; J.M.Q., CALÁBRIA, I.P.; VIEIRA, J.V.; MELO, B.; SANTANA, D.G.; SILVA, M.A.D. Desempenho de cultivares de cenoura no verão e outono-inverno em Uberlândia-MG. Horticultura Brasileira, v. 27, n. 1, p. 96-99, 2009.

MAROUELLI, W.A.; OLIVEIRA, R.A.; SILVA, W.L.C. Irrigação na cultura da cenoura. Embrapa Hortaliças, Brasília. 14p. 2007. (Embrapa Hortaliças. Circular Técnica, 48).

OLIVEIRA, C.D.; BRAZ, L.T.; BANZATTO, D.A. Adaptabilidade e estabilidade genotípica de genótipos de cenoura. Horticultura Brasileira, v. 23, n. 3, p. 743-748, 2005.

OLIVEIRA, C.D.; BRAZ, L.T.; BANZATTO, D.A. Adaptabilidade e estabilidade fenotípica de cultivares de cenoura. Horticultura Brasileira, v. 26, n. 1, p. 88-92, 2008.

RAJASEKARAN, L.R.; ASTATKIE, T.; CALDWELL, C. Seeding rate and seed spacing modulate root yield and recovery of slicer and dicer carrots differently. Scientia Horticulturae, v.107, n. 4, p. 319-324, 2006.

REGHIN, M.I.; DUDA, C. Efeito da época de semeadura em cultivares de cenoura. Ciências Exatas e da Terra, Ciência Agrárias e Engenharias, v. 6, n. 1, p.103-114, 2000.

SALGADO, A.S.; GUERRA, J.G.M.; ALMEIDA, D.L.; RIBEIRO, R.L.D., 
ESPINDOLA, J.A.Z.; SALGADO, J.A.A. Consórcios alface-cenoura e alface-rabanete sob manejo orgânico. Pesquisa Agropecuária Brasileira, v. 41, n.7, p. 1141-1147, 2006.

SANTOS, H.G.; JACOMINE, P.K.T.; ANJOS, L.H.C.; OLIVEIRA, V.A.; OLIVEIRA, J.B.; COELHO, M.R.; LUMBRERAS, J.F.; CUNHA, T.J.F. (Eds.). Sistema brasileiro de classificação de solos. 2. ed. Rio de Janeiro: Embrapa Solos, 2006. 306p.

SILVA, J.B.C.; VIEIRA, J.V.; MACHADO, C.M.M.; LIMA, G.B. Rendimento das cultivares de cenoura Alvorada e Nantes Forto cultivadas sob diferentes espaçamentos.
Horticultura Brasileira, v. 21, n. 2, p. 1-5, 2003. Suplemento.

SOUZA, J.L.; RESENDE, P.O. Manual de horticultura orgânica. Viçosa: Aprenda Fácil. 564p. 2003.

SOUZA, R.J.; MACHADO, A.Q.; GONÇALVES, L.D.; YURI, J.E.; MOTA, J.H.; RESENDE, G.M. Cultura da cenoura. Lavras: Editora UFLA, 2002. 68p. (Textos Acadêmicos, 22).

VILELA, N.J.; BORGES, I.O. Retrospectiva e situação atual da cenoura no Brasil. Brasília: Embrapa Hortaliças, 9p. 2008. (Circular Técnica, 